\title{
REVISÃO CLINICO-PRÁTICA DE POSTULADOS DOUTRINÁRIOS SÔBRE AS DEPRESSÕES
}

\author{
NELSON PIRES *
}

Característica comum das depressões é a baixa ou mesmo a perda de apetências.

Um acontecimento organísmico, cuja natureza ainda se ignora, provoca a depressão endógena; uma ocorrência desfavorável no mundo próprio do paciente provoca, em certos predispostos, uma depressão reativa; uma ocorrência orgânica - cerebral ou não, reversivel ou não - provoca em determinados indivíduos ora o que se pode chamar depressão orgânica ora o que se pode chamar de depressão sintomática. O potencial de vitalidade diverge de homem a homem. Alguns têm essa tensão vital sempre baixa; noutros as oscilações normais são exageradas para baixo (deprimidos constitucionais e distímicos depressivos). Portanto existem depressões endógenas, reativas, orgânicas, sintomáticas e constitucionais.

A análise de farto material de deprimidos, sobretudo extra-asilar, autoriza propor ainda a outra possibilidade cheia de litígios na história da Psiquiatria: a baixa e perda de apetências vai-se, com o fim da maturidade, anunciando ao homem como contingência intrìnsecamente humana, como fundo de cena permanente, embora de valência variável de caso para caso, quaisquer que sejam as condições orgânicas, ambientais, constitucionais ou hereditárias.

Progressivamente com o fim da idade madura, o homem se torna mais vulnerável à depressão e, progressivamente, êsse acontecimento depressivo - o declínio das apetências, se vai aprofundando e estendendo mais e mais a qualquer área da vida mental e corporal. A baixa das apetências é o estatudo natural que rege os que involuem e a depressão involutiva é a decorrente, mera sindrome de alarme e de adaptação à vida em extinção. O declínio das apetências, da vitalidade, a carência de futuro, a proximidade da morte compõem a problemática princeps do involutivo. Se se adicionam fatôres orgânicos ou ambientais ou endógenos, a dinamização dêles se processa em específica atmosfera ou transfundo sómato-psíquico-espiritual, regido pela vitalidade em crepúsculo. Nesses involutivos e velhos ora se percebe mais, na sintomatologia, a ação dos fatôres somáticos — hipertensão

Trabalho apresentado ao Colóquio Internacional sôbre Depressōes, realizado em Buenos Aires, em 21-23 março 1960.

* Catedrático de Psiquiatria na Fac. Med. da Univ. da Bahia. 
arterial, arterioscleroses e atrofia cerebral - ora a dos psicopatogênicos - as frustraçōes insuperáveis, vivências de declínio assimiladas com defeitos, vigência de fatôres espirituais - a inanidade dos valores que sustentaram até aí o sentido de vida e que mascaravam o "existir para a morte", afinal desnudado e vivido por experiência própria compulsória.

O transfundo depressivo fixo, tão evidente na involução não é o único. Também doenças crônicas, sobretudo quando comportam crises dolorosas ou sérias restrições nos rendimentos humanos normais - portadores de colopatias, seqüelas de traumatismos medulares, pronunciadas disfunçōes ovarianas, cardiopatias, megaesôfago, distúrbios metabólicos severos, por exemplo - configuram back-ground psíquico francamente propício às depressões. Ainda que o indivíduo não esteja sempre a lembrar-se dessas condições, claramente restritivas à sua existência, o transfundo depressivo é a constante, viva ou velada.

Também a miséria, a subalimentação, o desvalimento social e econômico, a vida na indigência e desproteção, preparam a depressão fácil com o transfundo do desespêro mal contido.

Nem sempre, êsses deprimidos se apresentam tristes; às vêzes são irritados ou resignados, embrutecidos ou apáticos, devaneadores ou irônicos e cáusticos. O Jeca Tatu, de Monteiro Lobato, foi fixado como tipo mais de resignado apático e inerte do que triste.

Para nós a baixa ou perda de apetências é o fenômeno clínico mais comum em tôdas as atuais depressões. A clássica tristeza, seja psíquica proclamada desde Kraepelin, seja corporal, motivo de debate entre K. Schneider e Bumke, pode faltar nas "depressio sine depressione", onde a depressão aparece mais como apatia, falta de animação psíquica, desencorajamento, tédio ou indiferença. Pode faltar o conhecido cortejo de ansiedade, inibição, lentidão de idéias e de psicomotilidade, agitação, delírio de culpa, ruína física ou econômica. Temos visto portadores dessa "tristeza corporal" em serviços de clínica médica não reconhecidos como tais. Muito mais que a "tristeza", hoje são vistas essas formas de recesso em si mesmo, diminuição das apetências e da iniciativa.

A depressão da psicose maniaco-depressiva, de conceito laborioso, da autoria de psiquiatras de hospicio é, hoje, para nós, a menos importante. Depois que a Psiquiatria saiu dos asilos e psicologizou-se ao exagero, aprendemos que as depressões extra-asilares são as mais freqüentes, as mais complexas, as mais graves, as de diagnóstico mais difícil, as que erguem problemas práticos e doutrinários mais duros e delicados.

\section{MATERIAL ESTUDADO}

Eis alguns números nossos referentes a doentes registrados em Serviço Psiquiátrico sediado num hospital geral, em Zona do Nordeste do Brasil.

Em 281 internados, 75 tinham a ver com a depressão; 12 vêzes a depressão da psicose maníaco-depressiva era o acometimento único no quadro 
mental; 63 vêzes, ou seja 5 vêzes mais, a depressão era reativa ou constitucional ou orgânica ou sintomática ou existencial (transfundo psíquico).

Em 174 doentes de ambulatório, 73 tinham a ver com a depressão; 3 vêzes a depressão da psicose maníaco-depressiva era o acontecimento único do quadro mental; 70 vêzes, ou seja, 23 vêzes mais, a depressão era uma das mencionadas acima.

Quanto à gravidade, em 12 suicídios consumados (tomados fora dêsse material), só um era portador de depressão endógena; em 8 tratava-se de depressão reativa em inseguro ou astênico; dos restantes, um era epiléptico cos distimias, um esquizofrênico e um alcoolista com delirium tremens. Havia, portanto, um endógeno contra 11 deprimidos de outra espécie. Em 11 casos de suicídio tentado e não consumado, havia 4 deprimidos endógenos, 5 reativos, um esquizofrênico e um alcoolista sem psicose; portanto, 4 endógenos contra 7 deprimidos de outra espécie.

Mesmo no imenso material de Ringel (Viena), de 745 pacientes que tentaram o suicídio, apenas 95 eram doentes mentais e, dêles, só 30 tinham depressão endógena, contra 65 psicóticos entre os quais 46 esquizofrênicos. Contra os 30 de depressão endógena havia 650 sem psicose e, dêles, 136 com doenças internas, todos êles a capitular, talvez, em um de nossos grupos mencionados. Daí se deduz que, em números absolutos, deprimidos por doença interna suicidam-se muito mais que os deprimidos endógenos puros.

Em nosso material, a depressão involutiva é, nos 281 internados com 75 depressões, aproximadamente da mesma freqüência que a depressão da PMD (10 involutivos e 12 PMD). Nos 174 pacientes de ambulatório com 73 deprimidos, havia 3 com PMD contra 20 involutivos. Em outro material de consultório, em 96 deprimidos havia 5 com PMD e 25 involutivos. Isto significa que, das depressões, a da PMD é realmente a menos importante, quanto ao número e quanto à gravidade, não nos aparecendo, portanto, como problema a exigir soluções prioritárias. Acresce que $85 \%$ das depressões da PMD tiveram remissão completa com o método de Cerletti, todos foram reconhecidos pela família ou pela triagem do hospital, como doentes de âmbito da Psiquiatria. O diagnóstico não ofereceu dificuldades maiores; a assistência foi, em média, curta.

O resto do material é muito mais numeroso; os grupos são mais complexos, às vêzes de catalogação difícil, de evolução extrema, desde os que vão à remissão espontânea e abandono da clínica, até aquêles menos sensíveis às terapêuticas empregadas (método de Cerletti, psicoterapia, psicoestimulantes). São aquêles 63 deprimidos internados e mais os 70 de ambulatório, aos quais adicionaremos 23 de outra procedência, perfazendo 156 deprimidos, dos quais 35 na involução. Às vêzes, são difíceis, mesmo, de identificar como deprimidos.

Verificamos nesse material que:

a) Só na minoria a depressão é tudo; na esmagadora maioria, a depressão é componente, maior ou menor, do quadro psíquico e psicossomático. 
b) Tanto há as clássicas depressões reativas, com evidente momento psicógeno desencadeador agudo, como há outras em que não se pode falar em desencadeador avulso e evidente. Nestas últimas, a vida se foi organizando sob condições desfavoráveis, embora não traumáticas, não agudas, mas contingentes à pobreza, ao isolamento, ao desvalimento econômico e desproteção social. Há um transfundo desfavorável, permanente, que dizemos normal ou habitual nas condiçōes sócio-econômico-culturais do Brasil e do Nordeste. Não são reações vivenciais anormais "psicoses de situação" da Psiquiatria clássica, com eventos situacionais extraordinários, mas formas de adaptação do sofrimento humano a condiçōes habituais regionais, geoeconômico-sociais desfavoráveis; chamamos a elas, olhando o que ensina Kurt Schneider (Hintergunddepressionen), modalidades de depressão de transfundo. Elas não são solucionáveis por técnicas terapêuticas. A maioria dos pacientes abandona o ambulatório por insuficiência do tratamento médico. Há, antes de tudo, um problema social e não médico estrito, nessas soi-disant depressões. Algumas vêzes, além de tudo, trata-se de carenciados e expoliados que melhoram se se trata dessa condição. Aliás, mencionaremos aqui que numerosas depressões psicógenas remitem com o electrochoque, o que poderá parecer heresia à psicologia clínica e ao apriorismo médico-acadêmico.

c) Outros pacientes procuraram-nos por ocasião de meras exacerbações depressivas ora autóctones, ora reativas, exaltações do modo de ser habitual, fàcilmente depressivo. A oscilação depressiva, tanto passa espontâneamente ou com auxílio medicamentoso, como se alonga e eterniza. Tanto o paciente abandona o ambulatório porque não mais precisa dêle, qualquer que tenha sido a terapêtica, real ou simples placebo, como se torna permanente no serviço clínico. São oscilações depressivas constitucionais, oscilações autóctones basais ou reativas curtas, ou prolongadas em desenvolvimentos progressivos. Temos doentes que se socorrem de medicamentos já seus conhecidos, em seus episódios igualmente bem conhecidos.

d) Depressōes em doenças internas, pois, pràticamente todo doente internístico ou cirúrgico vem a deprimir-se. Nem todos procuram médico e, menos ainda, o psiquiatra. A doença de que são portadores, ora alterou o cérebro, como na encefalopatia hipertensiva ou traumática, ora alterou o sentido de vida e a segurança do existir, como nos que tiveram enfarte do miocárdio ou nos cardiopatas.

Muitos pacientes (cronificados) do ambulatório peregrinaram por tôdas as clínicas do Hospital onde se descobriram pequenas anomalias que quase tôda gente suporta sem complicações. Mas não as suportam êsses doentes que se concentram no achado clínico e se petrificam na queixa hipocondriaca. Reduz-se nêles o Weltentwurf, anula-se o Umwelt, o projeto do mundo, o espaço do mundo retrai-se monstruosamente, como diz Binswanger, e a vida passa a gravitar só em tôrno da doença, na caçada aos sintomas e registro de sensações molestas. 
Pensando em Heidegger dizemos: êsses doentes estão reduzidos à contingência de "existir no corporal", última trincheira do ser-no-mundo, quando tôda a chance externa se anulou. Daí ao suicídio o passo é curto, como se deu em doente nosso que se fixara numa queixa de "enterocolopatia" como o disse a clínica médica - não grave e já de 8 anos; uma alta administrativa da enfermaria compeliu o paciente ao desamparo e a incendiar-se com gasolina.

Inumeráveis doentes pobres e crônicos de todos os ambulatórios vão lentamente organizando essa forma de hipocondria, de existir no corporal em progressiva autolimitação e liqüidação das apetências, apatia, silêncio subtotal da vitalidade, ou seja, depressão existencial. Aqui conjugam-se fatôres constitucionais, sociais, psíquicos e mesmo econômicos, na depressão.

Uma doente nossa teve, durante anos, tosse dita nervosa e incoercivel, rebelde à terapêutica, que a tornava molesta em casa, no trabalho e até no hospital; suicidou-se quando teve alta. Um marinheiro graduado tinha surtos de alergia, de anos de duração, com crises de esternutação de 15 a 20 minutos, diárias e repetidas; tal era a invalidez que não pôde sair do hospital por mais de ano; perdeu o emprêgo, a espôsa e o convívio habitual; vive agora isolado, confinado num vilarejo do interior de Minas Gerais.

e) Outras vêzes há queixas somáticas; não há doença interna e real, mas apenas suposta, lembrando novamente (como no item $c$ ) o rótulo, em vias de descrédito, de personalidade psicopática, sobretudo nas modalidades astênica, insegura, depressiva, lábil de humor. Estão aí contidos certos portadores de neuroses e de organoneuroses. Há os que têm conflito manifesto - por exemplo, desajustamento conjugal — e os que têm conflitos ocultos, não atentados, ignorados ou inconsciente (graves distúrbios da evolução da personalidade, homossexualidade latente, portadores de complexos de insuficiência, de frustrações antigas não superadas) ou de nitidas neuroses compulsivas e obsessivas. A depressão é sęcundária aos conflitos, como quer M. Bleuler, ou a depressão é secundária à neurose, como o simplificou Hans Hoff e é sabido de todos. Depressões ditas secundárias, mas que por 8 vêzes determinaram a morte entre os 12 suicidas de que falamos.

f) Outras vêzes, trata-se de involutivos onde os fatos até aqui mencionados se repetem com mais nitidez. Em alguns se salienta a componente orgânica da arteriosclerose cerebral, em outros a quebra do sentido existencial e a vivência inconformada do declínio universal dos rendimentos, em outros tudo se conjuga convergentemente, adicionado à tempetade vegetativa, como em certas pacientes em menopausa. Ora se trata de personalidades anteriores anormais - o que constituiu a maioria da casuística, ora de individuos que eram normais. O aumento da longevidade, naturalmente, aumenta a incidência e importância das depressões involutivas. Sabe-se que, no Brasil, pràticamente, não existe assistência especifica para os velhos e involutivos deprimidos; espera-os o hospital psiquiátrico comum. 
g) Finalmente há, em nosso material, uns quantos doentes mentais, onde a depressão despontava forte, como parcela do quadro mental; sobretudo esquizofrênicos, alcoolistas e epilépticos. Novamente lembramos que, por 3 vêzes em 12 casos, essa depressão-parcela levou à consumação do suicidio.

\section{COMENTARIOS}

A análise do material de deprimidos, de suicidios consumados e tentados, nos foi mostrando que a maioria dêsses casos que exigiu assistência médica, por vêzes imperativa, não coincide com o clàssicamente estabelecido pela Psiquiatria kraepeliniana e pela de asilo que lhe segue o balisamento. Só na minoria de casos, a tristeza alçava-se saliente e límpida, como na maioria dos quadros endógenos puros. O suicídio de alguns de nossos doentes não endógenos foi surprêsa para nós.

O aspecto depressivo - a perda de apetências - podia estar mascarado por queixas de primeiro plano, inclusive somáticas reais ou não, ou oculto atrás de irritação, mau humor, agressividade, ironia ferina, serenidade forçada, fantasias, rigidez de apreciações, etc., inclusive, como se deu em certos casos, até poucos dias antes do suicídio. Conhecemos suicida, homem corretíssimo, que denunciava colegas seus a sançōes penais, dias antes de tentar suicidar-se. Parece-nos ser esta a principal via de acesso ao diagnóstico diferencial com as depressões endógenas. Em tôdas as não endógenas, é sempre possível complicar-se a dinâmica defensiva contra a depressão: na depressão endógena, a tristeza-se alça-se quase sempre originária, desembaraçada, registrada como tristeza livre, nitida, pura, saliente, clara; em outras palavras, o acontecimento depressivo é, nas depressões endógenas, mais extrinseco à personalidade anterior, sendo, qualitativamente, diverso das demais depressōes, como tantos autores o dizem.

Nosso material permite observar uma imensa gradação de matizes nas depressões - desde as que merecem o diagnóstico unidimensional de depressão "tout court" (endógena ou reativa, ou outra) até os casos em que a componente depressiva é parcial no quadro e só pode ser mencionada se se faz diagnóstico polidimensional.

Finalmente, há um tipo de conduta que não mais justifica qualquer diagnóstico: uma depressão habitualmente extramédica, pois que, sob o signo da depressão organizou-se e acomodou-se o destino do paciente, e só se poderia qualificá-lo como "forma depressiva de existir".

Em muitos casos, a apatia e indiferença lentamente organizada é, com efeito, uma sindrome de adaptação e auto-proteção contra um destino extremamente opressivo e sem esperança. Muitos dêsses pacientes vão à consulta uma ou duas vêzes e logo dispensam o tecnicismo assistencial, voltando à muda resignação, ao auto-apagamento, à religião e às seitas populares. Outros, nunca pensaram em recursos clínicos face a seu desvalimen- 
to, e nem sequer têm insight da depressão, brutalizados pela condição de esmagados pela vida.

Existem pacientes que não cogitam de médico, não se julgando passíveis de tratamento, não acreditando que seu organizado destino de execução vivencial depressiva possa ser alterado com a exigüidade dos recursos clinicos ou psicológicos. Muitas velhos solitários, alcoolistas decaídos e inveterados, tuberculosos graves, doentes incuráveis de todo tipo, párias e mendigos, inválidos, mutilados, expatriados empobrecidos, cegos e abandonados, etc., estão nesse caso, vegetando apáticos e indiferentes, até embrutecidos, como suicidas sem pressa. Os que estudaram o suicídio sabem que a grande maioria dos que se matam, nem era doente mental nem se julgava na órbita da Medicina que alcança, apenas, uma quota muito reduzida da totalidade dos deprimidos, nem sempre a porção mais grave, só a mais acadêmica e a de valor humano mais negativo. Mais negativo porque $o$ ir ao médico pode significar uma confessada falência e incapacidade de auto-regular o destino pessoal; incapacidade que recorria antigamente à Deus e à religião e que recorre agora, cada vez mais, à técnica e à magia do medicamento e do médico.

\section{RESUMO}

O autor, que trabalha no Nordeste do Brasil, em área marcadamente "subdesenvolvida", vale-se de material recolhido em sua clinica universitária (Hospital Geral), tanto de ambulatório (73 doentes), como de internados (75 doentes), como ainda de 23 de clínica privada. O grupo menos numeroso é o de deprimidos endógenos, 20 (psicose maniaco-depressiva), seguido dos 55 involutivos e dos 81 de outra natureza. Em 12 suicidas apenas um era deprimido endógeno e em 11 que tentaram o suicídio, só 4 eram endógenos. Daí deduz o autor que a depressão endógena é atualmente em sua região a menos freqüente e a menos grav̀e das depressões, fato confirmado também pelo maior índice de remissões nesse tido de depressão. Talvez a facilidade maior do diagnóstico dessa forma junto à excelência da terapêutica convulsiva, explique a maior presteza, precisão e o êxito usual do tratamento. No material do autor, a depressão involutiva se apresenta, como em tôda parte, como problema de gravidade crescente devido ao.aumento da longevidade e da inexistência de assistência organizada aos velhos em nossa região.

O grupo mais importante de depressões é, agora, pràticamente o das reativas, e o das chamadas "depressões de transfundo" (Hintergrunkreaktionen de Kurt Schneider), depressão muitas vêzes assestada em portadores de doenças internas. As ditas "depressões neuróticas" estão incluídas nas reativas. Aliás fixou-se, no material do autor, o fato da depressão ser tudo no quadro mental ora ser apenas componente parcelar dêle, o que é muito mais freqüente e mais grave como as cifras de suicídio o mostram. O autor verificou que os casos mais difíceis de assistir com êxito são aquêles onde 
as condições de pauperismo, subalimentação, desproteção social, falta de instrução e de profissão vão organizando "estilos de vida", sem esperança, levando o homem à apatia, resignação, passividade e inércia ou a formas de vida restritas ao corpo, ditas em filosofia existencial - "existir no corporal". A miséria em todos os sentidos vai configurando o "transfundo" fixo da existência, exigindo adaptação à falta de tudo o que leva à paralisia das apetências. Nossa literatura já fixou há muito tempo o "Jeca Tatu" fatalista e inerte. A Psiquiatria antiga proclamava a tristeza como o sintoma cardinal da depressão. O autor em sua casuística mostra que, em vez disso, a constante maior é agora a perda de apetências com e sem tristeza, ou seja, a forma de viver na apatia, no desânimo, na indiferença, no conformismo resignado e restritivo ou na agressividade e sofisticação adquiridos compulsòriamente tanto por condições econômico-sociais, como por doença interna, invalidez, doenças dolorosas ou fortemente restritivas do convívio, aviltamento da existência, conflitos, doenças incuráveis ou pelo aniquilamento lento e vivido sem conformismo, dadas as condições de declínio e velhice. A perda do "sentido de vida" é o denominador comum. A maioria dos deprimidos não é mais alcançada pela Psiquiatria e circula sem "insight" no meio social, ignorando a sua condição de deprimido ou de desesperado ou recorre à religião e às seitas primitivas ou simplesmente se acomoda ao autoapagamento ou reage com fórmula própria, mascarando a depressão com irritação, queixumes, agressividade, sofisticação e até delinqüência ou suicídio sem procurar médico; outra porção de deprimidos vai aos hospitais e a tôdas as clínicas e ambulatórios e cedo ou tarde se convence da inutilidade dos recursos médicos face às dimensões de suas dificuldades reais insolúveis pela medicina e abandona o tratamento exclusivamente técnico. Os que procuram o psiquiatra em boa parte são os mais esclarecidos e esperançosos da tecnologia, mas também os que, por incapacidade confessada de dirigir-se, procuram conselho e apoio do médico e dos remédios. Os deprimidos comumente estudados pela Psiquiatria clássica são os mais "acadêmicos" da série depressiva. A Psiquiatria clássica os divide em endógenos, reativos, constitucionais, sintomáticos e orgânicos. As depressōes de transfundo e a existencial foram, no trabalho do autor, inspiradas em Kurt Schneider e Ludwig Binswanger.

\section{SUMMARY}

Criticism of practical-clinical postulates on depressions.

The author, who works in the Northeast of Brazil, in an area noted for its underdevelopment, has gathered data mainly from his university clinic (general hospital), out-patient (73 patients) hospitalized cases (75 patients) and also from patients in his private clinic. The group with the lowest number is the "endogenous depressed" (20 manic depressive psychoses) followed by 55 senile and 81 of other types. Out of 12 suicides, only one was of the "endogenous depressed" group and out of 11 who tried to commit 
suicide, only 4 were of the "endogenous" group. From this the author has deduced that the "endogenous depressed" in his region is currently the less frequent and less serious of the depression cases; this fact has also been confirmed by the higher rate of remissions in this type of depression. Perhaps the easier means of diagnosis in this type of depression as well as the excellence of the convulsive therapy explains the promptness, precision and the usual success of the treatment. In the author's report senile depression is presented, as in all other parts of the world, as a problem of increasing severity due to the increase in longevity and the lack of organized assistance for the aged in our region.

The most important of the "depression" groups are now the psychoneurotics and the so called "background depressions" (Hintergrundreaktionen - K. Schneider) depressions often found in patients with internal ailments (the so-called "psychoneurotic depressions" are included in the "reactives"). From the author's report it is apparent that depression is all important in the mental picture even though it is only a component part of it, which is much more frequent and more serious, as statistics on suicide have shown. The author has verified that the most difficult cases to successfully help are those where conditions of poverty, malnutrition, social abandonment, lack of education and profession are creating "modes of life" without hope, leading men to apathy, resignation, passivity and inertia or forming ways of life restricted to the body patterned after existential phylosophy "to exist in the body". Misery in every sense is changing the aspect of existence, demanding adaptation to a lack of everything which leads to the paralysis of desires. For some time our literature has established the character called "Jeca Tatu" who is incrt and fatalistic. In the old days, psychiatry proclaimed grief as a primary symptom of depression. The author in his "summing up" has shown that instead of this, what is more prevalent nowadays is the loss of desire with or without grief. This means a way of living in apathy, despair, indifference, in resigned and restrictive conformity or in aggressiveness and sophistication compulsively acquired as much through social-economic conditions as by internal ailments, invalidism, painfull illnesses or strongly restrictive associations; contempt for existence, conflicts, incurable diseases or by gradual annihilation and living in nonconformity from the conditions of decline and old age. The loss of "significance in life" is the common denominator. The majority of the depressed are no longer reached through psychiatry and circulate without "insight" in the social sphere, ignoring their depression or despair, embracing religion or the primitive sects of being content to conform themselves to self slow and passive extinction. Each reacts in his own way masking depression with irritation, complaints, aggressiveness, sophistication, and even delinquency or suicide without seeking for medical aid. Another group of depressed patients will go to all the hospitals and clinics and sooner or later are convinced of the inability to medical resources to solve their tremendous problems and abandon technical treatment. The majority of those who seek 
psychiatric help are the more enlightened and hopeful that the technique will prove successful but also those who confess that they are unable to manage their own lives look for counsel and support from the doctor and also from medication. The group of depressed patients most frequently studied by classic psychiatry are the traditional of the depressed group. Classic psychiatry divides the depressed into the following groups: endogenous, psychogenic and psychoneurotics, constitutional, symptomatic and organic. The background depression and the existential mentioned in the author's work were inspired by Kurt Schneider and Ludwig Binswanger.

Rua Aquidabã, 25 - Cidade do Salvador - BA, Brasil. 